DIW BERLIN

Discussion Papers
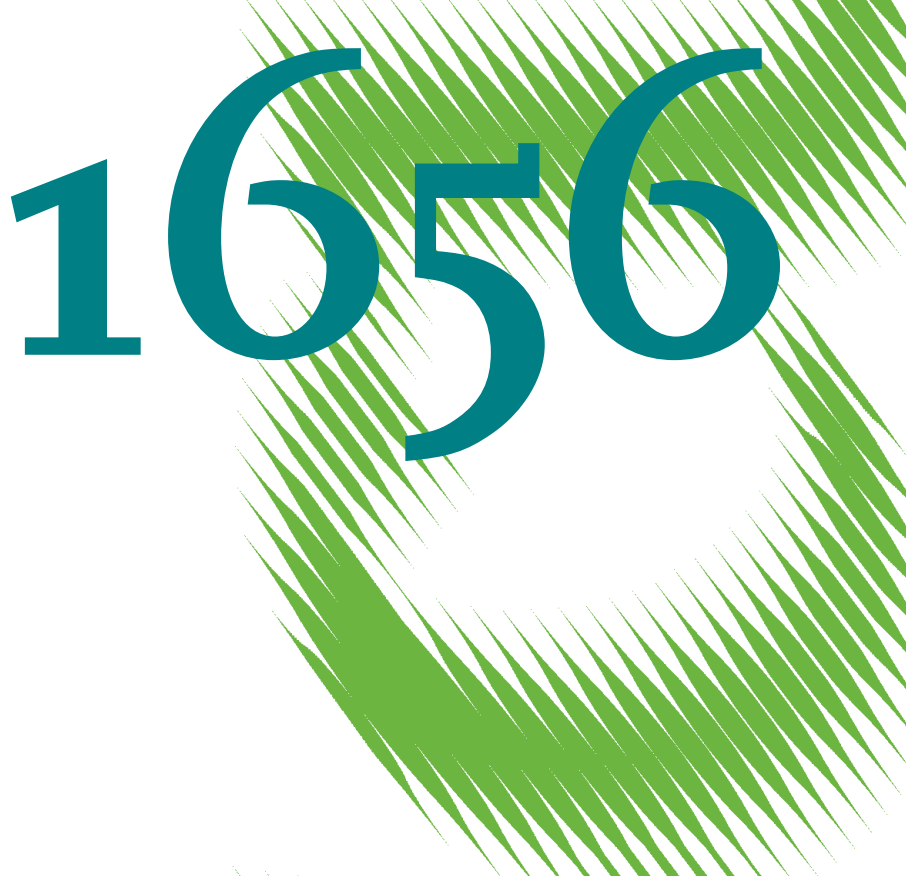

Balancing Reserves within a Decarbonized European Electricity System in 2050 - From Market Developments to Model Insights 
Opinions expressed in this paper are those of the author(s) and do not necessarily reflect views of the institute.

IMPRESSUM

(C) DIW Berlin, 2017

DIW Berlin

German Institute for Economic Research

Mohrenstr. 58

10117 Berlin

Tel. +49 (30) $89789-0$

Fax +49 (30) $89789-200$

http://www.diw.de

ISSN electronic edition 1619-4535

Papers can be downloaded free of charge from the DIW Berlin website:

http://www.diw.de/discussionpapers

Discussion Papers of DIW Berlin are indexed in RePEc and SSRN:

http://ideas.repec.org/s/diw/diwwpp.html

http://www.ssrn.com/link/DIW-Berlin-German-Inst-Econ-Res.html 


\title{
Balancing reserves within a decarbonized European electricity system in 2050 - From market developments to model insights
}

\author{
Casimir Lorenz ${ }^{* \dagger}$
}

March 30, 2017

\begin{abstract}
This paper expands the discussion about future balancing reserve provision to the long-term perspective of 2050. Most pathways for a transformation towards a decarbonized electricity sector rely on very high shares of fluctuating renewables. This can be a challenge for the provision of balancing reserves, although their influence on the balancing cost is unclear. Apart from the transformation of the generation portfolio, various technical and regulatory developments within the balancing framework might further influence balancing costs: i) dynamic dimensioning of balancing reserves, ii) provision by fluctuating renewables or new (battery) storage technologies, and iii) exchange of balancing reserves between balancing zones. The first part of this paper discusses and transforms these developments into quantitative scenario definitions. The second part applies these scenarios to dynELMOD (dynamic Electricity Model), an investment model of the European electricity system that is extended to include balancing reserve provision. In contrast to other models applied in most papers on balancing reserves, this model is capable of evaluating the interdependencies between developments in balancing reserve provision and high shares of fluctuating renewables jointly.

The results show that balancing reserve cost can be kept at current levels for a renewable electricity system until 2050, when using a dynamic reserve sizing horizon. Apart from the sizing horizon, storage capacity withholding duration and additional balancing demand from RES are the main driver of balancing costs. Renewables participation in balancing provision is mainly important for negative reserves, while storages play an important role for the provision of positive reserves. However, only on very few occasions, additional storage investments are required for balancing reserve provision, as most of the time sufficient storage capacities are available in the electricity system.
\end{abstract}

JEL Codes: Q42, Q47, Q48, C61, L94

Keywords: balancing reserves, electricity sector modeling, investment model, renewable participation, cross-border cooperation, dynamic sizing.

\footnotetext{
*clorenz@diw.de, German Institute for Economic Research (DIW Berlin), Department of Energy, Transportation, Environment, Mohrenstraße 58, 10117 Berlin.

${ }^{\dagger}$ Berlin University of Technology, Workgroup for Infrastructure Policy (WIP), Straße des 17. Juni 135, 10623 Berlin.
} 


\section{Introduction}

To be able to adhere to the target of the Paris Agreement (UNFCCC, 2015) the European electricity sector must be decarbonized, implying a transformation of the generation portfolio. Depending on assumptions regarding the cost and availability of nuclear electricity generation and carbon capture, transport and storage (CCTS) technologies, different pathways for this transformation are suggested by science and politics. Most pathways include very high shares of fluctuating renewable energy sources (RES) until 2050. These shares can be a challenge for generation capacity adequacy because of their daily and seasonal variability of the feed-in. This medium and long-term variability is not the only challenge: fluctuating RES are regularly deviate from their planned production schedules. These short-term deviations must be balanced out by the activation of balancing reserves. Hence, an increasing RES share will, most probably, lead to an increasing balancing reserve demand (despite forecast quality improvements, see section 2.1 for a detailed discussion). Furthermore, a large share of balancing reserves are still provided by fossil-fueled generation, which will be phased-out by 2050 under a decarbonization target. These challenges resulting from balancing provision are neglected in most investment models and will therefore be analyzed in detail in this paper.

To reduce the cost of balancing reserve provision, multi-national cooperations have been formed, new technologies participate in balancing reserve provision, and a large part of the regulatory framework has changed. Falling prices in spot and forward markets have motivated more and more generators to participate in the relatively, profitable balancing markets. Nevertheless the provision of balancing reserves and the balancing markets are a technically and regulatory highly complex field which still offers large room for developments and harmonization of the framework across Europe.

In the first part of this paper, these developments of the framework for balancing reserve provision are analyzed with a focus on: i) dynamic dimensioning of the demand for balancing reserves, ii) provision of balancing reserves by fluctuating renewable electricity sources, iii) the role of new (battery) storage technologies, and iv) possible exchanges of balancing reserves between balancing zones and joint procurement of balancing reserves. See Section 2 for a detailed review on the possible developments and their transformation into scenarios. These scenarios are applied to an enhanced version of dynELMOD (dynamic Electricity Model), an investment model of the European electricity system (see Gerbaulet and Lorenz (2017)), that is extended to include balancing reserve provision. The model is capable of evaluating the effects of possible developments in balancing reserve provision and high shares of fluctuating RES jointly. Hence, it allows me to analyze the future cost of balancing reserve provision in a decarbonized electricity system while evaluating the influence of different developments within the technical and regulatory framework of balancing.

There are several options to analyze balancing markets based on electricity system models. In general, electricity system models can be categorized either as long-term planning models or short-term operation models. Large-scale and long-term planning models are mainly used 
to determine cost-efficient investments pathways for generation and transmission capacities. To allow for this large scope they abstract from some technical details and neglect some operational issues (Hagspiel et al., 2014; Ludig et al., 2011; Mantzos and Wiesenthal, 2016). Most studies analyze the effect of different policies or technologies on the spot and balancing markets in a unit-commitment model which does not allow for endogenous capacity investments (Farahmand and Doorman, 2012; Gebrekiros et al., 2015; Spieker et al., 2016).

Only very few studies analyze the future balancing provision in dynamic large scale electricity system models that includes endogenous capacity investments. Zerrahn and Schill (2015) develop a greenfield model that includes balancing reservation. It is a single node application and roughly calibrated with German input data and cost assumptions for 2050. Similarly, Belderbos and Delarue (2015) present a model that allows for endogenous investment planning with operational constraints. However, in both papers, the implications of the balancing constraints have not been analyzed systematically and no large-scale brown field application is done due to computational limits.

Most similar to the analysis presented in this paper, van Stiphout et al. (2017) analyze the impact of balancing reserves on investment planning within electricity systems with a high RES target. Their hypothesis is that in the existing literature the technical barriers and integration cost of large shares of RES are underestimated as in most long-term electricity models balancing reserves are not included. To test their hypothesis, they develop an endogenous greenfield investment model that includes detailed constraints for system operation. The model is applied to a conceptual test system that is roughly calibrated to the Belgian power system. Their results confirm their assumption, that the necessary balancing reserve requirements will lead to substantial additional cost for the integration of large shares of RES. Even a rather unambitious RES generation share of $50 \%$ would lead to a dramatic total system cost increase of up to $30 \%$. This is due to necessary reserves, assuming no change of the currently existing balancing framework conditions. Even with possible improvements in the balancing market (RES participation and dynamic reserve sizing) the total system cost would still go up by $20 \%$. These high costs can possibly be explained by the following simplifications of van Stiphout et al. (2017) in comparison to this paper: i) only three generic generation technologies, ii) no other countries, iii) no electricity grid, iv) no upward reserve provision from RES, v) no storage or demand side management (DSM), and vi) no biomass or hydro generation capacities.

The reminder of the paper is structured as follows: Section 2 analyzes future developments within the technological and regulatory framework of balancing reserve provision and transforms them into quantitative scenarios. These scenarios are applied to the electricity system model dynELMOD that is presented in Section 3. The model includes a large-scale data set of the European electricity system, described in Section 4. In Section 5 the model results for the scenarios and sensitivities of the different developments are analyzed and Section 6 concludes. 


\section{Balancing market developments}

The balancing market is influenced by the following developments: i) steady technical progress in weather forecasts for fluctuating RES, reducing their balancing reserve demand, ii) fluctuating RES increase their potential to participate in the balancing reserve provision (Hirth and Ziegenhagen, 2015), iii) prices for battery storages decrease rapidly and allow for further applications in balancing markets (Nykvist and Nilsson, 2015), and iv) the regulatory framework changes to enhance cross-border exchange and foster harmonization between markets (EC, 2017). In the following, these developments of the framework for balancing reserve provision will be analyzed in detail. With this analysis, factors that could influence the model outcome regarding balancing reserve provision will be identified. These factors will be summarized in assumptions that will be varied in the different scenarios and sensitivities described in Sections 2.1 to 2.4.

\subsection{Balancing reserve dimensioning and sizing horizon}

When determining the size of the necessary balancing reserve, the aim is to dimension the reserves as small as possible to reduce the cost for reserving capacity, but as big as necessary to reduce the risk of insufficient reserves to balance the electricity system. Reserve sizing methodologies can be characterized by their sizing approach and sizing horizon. The sizing approach can be either deterministic (e.g. based on the possible failure of the largest power plant in the synchronous system), heuristic (e.g. using a formula accounting for system characteristics and empiric coefficients) or probabilistic (based on a probability distribution of system imbalances). The heuristic and deterministic sizing approach is usually combined with a static sizing horizon. The static sizing horizon determines the necessary reserves for relatively long time periods ranging between days and a full year. The probabilistic approach can be used with a static and a dynamic sizing horizon. The dynamic sizing horizon includes much shorter time period than the static horizon. The reserves can be resized (e.g. every day for each of the next 24 hours), based on the latest forecast of RES in-feed. Therefore not the full theoretical generation capacity is included, hence, only the probability of forecast deviation of a much lower capacity must be included. Especially for systems with high shares of RES, the reserves can be reduced significantly with a dynamic horizon. (Holttinen et al., 2012)

The impact of increasing shares of RES on balancing reserve provision is still in discussion: most studies assume that, due to the fluctuating nature of wind and solar power, the demand for balancing reserve capacity increases in order to compensate for forecast errors (Papavasiliou et al., 2011). The estimates in the literature for the additional reserve demand caused by additional wind capacity are in the range of $2 \%$ to $9 \%$ (Brouwer et al., 2014; dena, 2010; DLR, 2012; Holttinen et al., 2011; Lew et al., 2013). Ziegenhagen (2013) estimates an additional reserve demand of $6 \%$ of the installed wind capacity which can be decreased to about $4 \%$ with additional solar installation. To account for the uncertainty within the literature I vary the additional balancing 
demand per GW of fluctuating RES (referred in the following as "RES demand factor") in our different scenarios and sensitivities (see Section 2.4).

For the German balancing market, a continuation with a static sizing horizon and a high RES share, as it is projected for 2030, would lead to a balancing reserve demand increase between $25 \%$ and $75 \%$ dependent on assumptions regarding forecast quality improvements for RES (Bucksteeg et al., 2016; Kays et al., 2010). With a dynamic sizing horizon the balancing reserve demand increase would be limited to 5\%-15\% (Bucksteeg et al., 2016).

Contrary to the literature, the absolute value of reserved balancing capacity decreased in Germany in the years 2010-2015, although renewable capacity increased significantly. At the same time, restructuring of the market and regulations lead to efficiency gains. Morbee et al. (2013) and Ortega-Vazquez and Kirschen (2009) present a further explanation and show show that until a high share of RES is reached, no significant effect on the demand for balancing reserves need to be expected.

The implementation of such reserve sizing calculations in a large-scale investment model leads to difficulties: the probabilistic calculation of balancing reserves is non-convex due to the convolution of probability distribution functions. For this calculation the installed capacities of the technologies (in this case wind onshore, wind offshore and photovoltaic (PV)) must be know. These capacities are endogenous in an investment model and hence not known beforehand. Because of the non-convexity of the sizing approach, it can not be included in an investment model due to computational limits. Therefore a possible reduction of balancing reserve demand due to stochastic independent deviations by different technologies is underestimated.

\subsection{Renewables and storage as new market participants}

Regularly only dispatchable power plants were allowed by the transmission system operator (TSO) to provide balancing reserves. However, this changed and also non-dispatchable technologies are allowed as new possible providers of balancing reserves. This includes electrode boilers, large customers, battery storages, virtual power plants and also fluctuating RES. The potential for battery storage and fluctuating RES will be analyzed in detail.

The provision of balancing reserves by RES is not longer a technical problem (EWEA, 2014; Gesino, 2011). Wind (on and offshore) have successfully passed the pre-qualification procedure, which certifies their sufficiently fast response time and controllability, to participate in German balancing markets (50Hertz, 2016). Similarly PV is able to provide part of its capacity in the balancing market (Jansen and Speckmann, 2013). As discussed in Hirth and Ziegenhagen (2015) and Sorknæs et al. (2013) fluctuating RES will most likely supply negative balancing reserves in the next years. However, for hours of excess electricity production, it makes sense for RES also to provide positive reserves. During these times, withholding generation from RES for balancing reserves leads to no opportunity cost, as they would be curtailed anyhow (EWEA, 2014). If the hours of excess electricity production will continue to increase in the upcoming years, an increasing share of positive balancing reserves could be provided by fluctuating RES. 
Fluctuating RES include a special challenge as their final production always includes risk. Due to this risk, not the full forecasted generation can be reserved for balancing provision. To reach the same security level of dispatchable power plants, the share that can be used for balancing reserve is dependent on the forecast quality of the feed-in. As a result, long before delivery very few capacity can be reserved, as the forecast has a high deviation probability.

As time of delivery approaches, forecast quality is higher and more capacity can be used for balancing provision. Therefore currently common lead times of a week and product lengths of days, as in Germany, are too long. As a result, single units must currently be in a pool with sufficient dispatchable generation to be able to participate.

Götz and Baumgart (2014) conclude, that for an security level of $99.994 \%$ up to $30 \%$ of the entire German wind power feed-in is firm, when all turbines are pooled. A similar analysis by Fraunhofer IWES (2014) estimates a share of $10 \%$ of the feed-in that would be available for balancing services in a day-ahead regime. This share is referred to the "firm capacity forecast" and varied in the different scenarios and sensitivities (see section 4).

Besides fluctuating RES, battery storage entered the balancing reserve market in 2015. Largescale batteries are already used for the provision of frequency containment reserve (FCR), and a market share of $27 \%$ is expected by the end of 2017 (Fleer et al., 2016). Due to rapidly falling battery prices, it could become economic, that storage will also provide frequency restoration reserve (FRR). Brijs et al. (2016) show that considering battery storage for balancing services is beneficial and reduces the total system cost (TSC). For the profitability of storages in balancing market, it is decisive for how many subsequent hours the battery storage must be able to provide its reserves. This implies how often it will be possible to activate the balancing reserves in a row without unplanned recharges. The duration a balancing reservation is influencing the storage level constraints is referred as the "storage reservation window".

The storage reservation window describes the length for which balancing reservation is influencing the storage level constraints (see Section 3.2 for the mathematical formulation). In Figure 1 , the influence of this constraint is demonstrated for a storage reservation window of six hours with an exemplary storage consisting of 100MW charge and recharge capacity and a storage volume of 100MWh. In the upper graph a fictional positive and negative reservation is depicted. Every reservation narrows the gap between the minimum and maximum storage level, as depicted in the lower graph. The solution space for the storage level is defined as the area between the gray and blue line. From hour eight on the minimum storage level decreases, as the positive reservation in hours one (and following) falls out of the storage reservation window. I vary the storage reservation window in the different scenarios and sensitivities (see Section 4).

\subsection{Cross-border cooperation}

When the electricity grids within Europe have been interconnected and synchronized one reason was to increase the system stability and security. Another reason was the possibility to trade electricity over these interconnectors (ICs). The trade of electricity normally reduces the TSC 


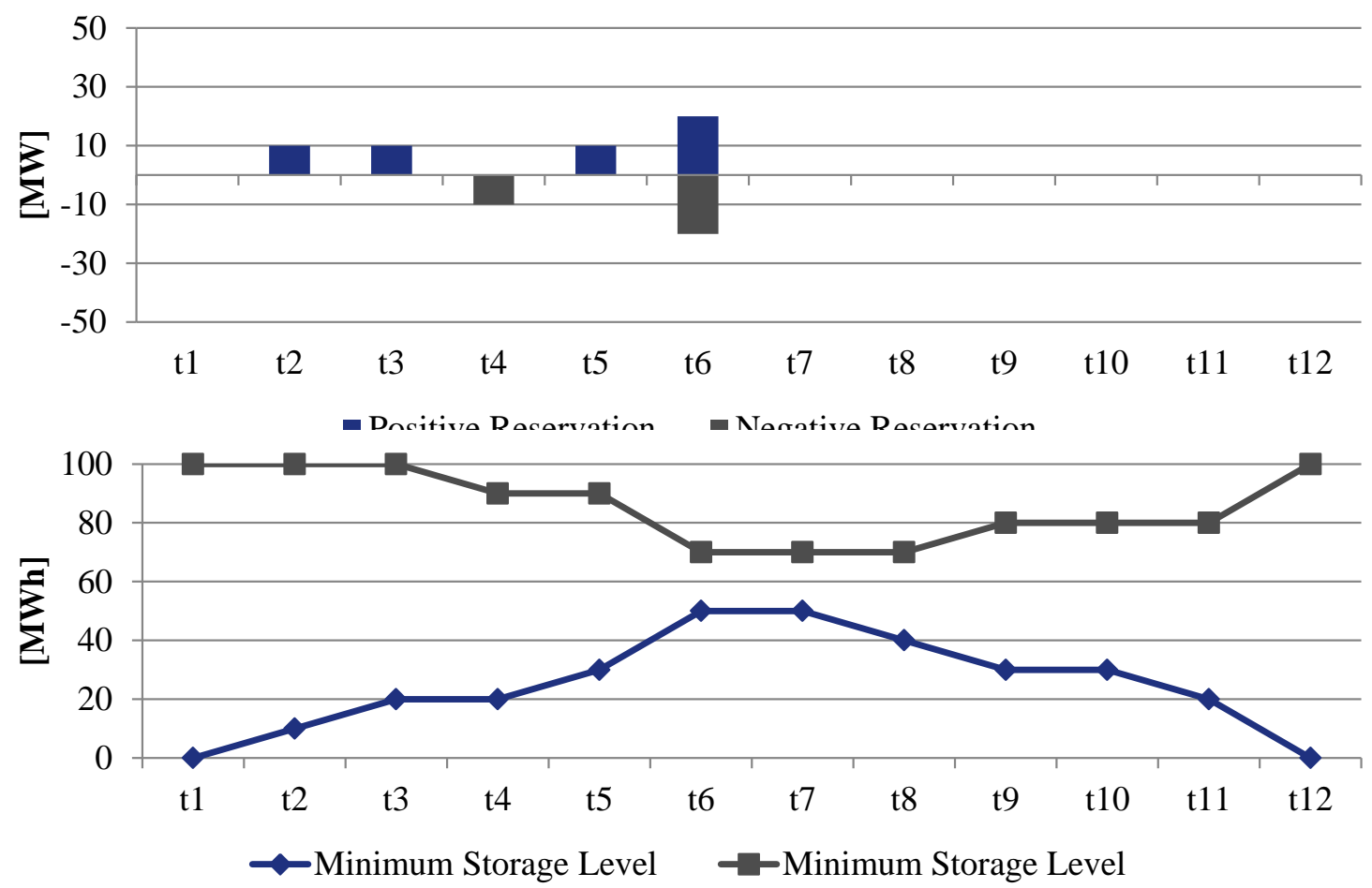

Figure 1: Influence of positive and negative balancing reservation on the storage level constraints

as it allows to use generation portfolio more efficiently. Besides the trade of electricity, the ICs allow for cross-border cooperation between the TSOs for the provision and activation of balancing reserves.

Different degrees of cross-border cooperation are possible between the TSOs. The options are characterized by different regulatory and technical complexity but also resulting levels of benefits. The first option refers to imbalance netting. Imbalance netting describes the process of netting positive and negative imbalances in the cooperating control zones. Thereby the imbalance of both zones can be reduced if the imbalances in at least two zones have a different sign. Imbalance netting is performed at the point in time when the imbalance occurrs and transmission capacity is available. Hence, neither the balancing reservation nor the balancing activation merit-order is influenced. Therefore this option requires the least technical and regulatory interventions.

The second option is a joint activation of reserves, that normally comes after imbalance netting. This option allows to use a common merit-order list for two or more cooperating balancing zones. Therefore the power plant that is activated must not be in the same zone where the imbalance occurs, if sufficient transmission capacity is available. Due to the common merit-order it is more complex than imbalance netting; still the allocation of the reserved capacities is not influenced. The third option is the joint procurement of balancing reserves, that only makes sense if the two other options are already implemented. This option results in a common market which is only limited by cross-border transmission capacity. In contrast to the other options, this transmission 
capacity must be known before. This could make the reservation of IC capacity necessary, which is then not longer available for the spot market. Hence, a joint optimization of balancing and spot market IC capacity usage is important to set the cost-efficient share between the two.

The benefits and implications of cross-border exchange of balancing reserves have been studied in various papers: Van der Veen et al. (2010) give an overview on main cross-border balancing agreements and conclude that cross-border balancing agreements are generally positive, but the impact depends on the detailed balancing market design. Farahmand and Doorman (2012) estimate cost savings of up to 400 million $€$ per year resulting from an integration of the Nordic balancing market with the German balancing market. A further approach to analyze the reserve procurement and transmission capacity reservation in the northern European power market is shown by Gebrekiros et al. (2015). They confirm that balancing provision cost can be reduced when transmission capacity is reserved. With a transmission capacity reservation level of around $20 \%$, total system cost tend to be the lowest. Lorenz and Gerbaulet (2017) analyzes different degrees of balancing cooperation between Austria, Germany and Switzerland. They show that joint procurement of balancing reserves allows for much larger cost savings than imbalance netting or joint activation only. In the optimal setting, balancing power cost can be reduced by up to $40 \%$. They conclude, that currently existing imbalance netting should be expanded towards the joint procurement of balancing reserves.

European Network of Transmission System Operators for Electricity (ENTSO-E) also acknowledges the need to foster and regulate cross-border exchange of balancing services (ENTSO-E, 2012). To regulate possible cross-border cooperations, ENTSO-E formulated the Network Code on Electricity Balancing (NC EB), which foresees arrangements to promote cross-border exchange of balancing services with the objective of lowering overall costs and increasing social welfare. Therefore, it address the topics of i) imbalance settlement, ii) joint procurement of balancing services, and iii) reservation and use of cross-zonal capacity for balancing (EC, 2017). In 2017, eight pilot projects tackle these problems for the different balancing products (FCR, FRR and replacement reserve (RR)) (ENTSO-E, 2014). The International Grid Control Cooperation (IGCC) is one of them and consists of eleven TSOs from central and west Europe and allows for imbalance netting. Another balancing pilot project is the Trans European Replacement Reserves Exchange (TERRE) project, whose objectives is to establish a platform for all RR offers and to optimize the allocation of RR across the systems of various TSOs (ENTSO-E, 2015). Furthermore, the EXPLORE project aims at creating a consistent cross-border balancing market design for automatic frequency restoration reserve (aFRR) and manual frequency restoration reserve (mFRR) while taking into account possible interlinking between spot and balancing market (50Hertz et al., 2016).

The question remains, whether there is a limit on balancing exchanges. The secure supply of balancing reserves is crucial for system stability. Hence, it must be guaranteed that the reserved balancing capacities can also be delivered. Therefore the unplanned reduction of IC capacity can put the whole electricity system at risk. However, this can also happen within a control zone. Therefore, the reserves must be allocated in such a way, that enough redundant transmission 
pathways are possible (in line with the $\mathrm{n}-1$ criteria). I vary the maximum amount of reserves that can be exchanged, which in the following is referred to as "maximum exchanges".

\subsection{Scenarios and sensitivities}

The future technical and regulatory framework for balancing reserve provision is uncertain, as shown in the previous analysis in Section 2. The analysis identified the following factors as most critical:

1. Static or dynamic sizing horizon for balancing reserves;

2. Reserve demand in percent of each additionally installed GW of fluctuating RES;

3. Firm capacity forecast in percent of RES feed-in forecast;

4. Storage reservation window in hours;

5. Maximum cross border balancing reserve exchange in percent of total reserve demand;

The factors are combined in three scenarios pessimistic, conservative and optimistic. Additionally, each factor will be analyzed in a separate sensitivity analysis based on the conservative scenario. Table 1 gives an overview on scenarios and sensitivities. Max and min are not tested in joint scenarios but are only used as worst case and optimal case for the sensitivity analysis.

Table 1: Scenarios and sensitivities

\begin{tabular}{lccccc}
\hline & Max & Pessimistic & Conservative & Optimistic & Min \\
\hline Dynamic sizing horizon & & yes/no & yes $/$ no & yes $/$ no & \\
RES demand factor & $10 \%$ & $8 \%$ & $6 \%$ & $4 \%$ & $2 \%$ \\
Firm capacity forecast & $5 \%$ & $10 \%$ & $20 \%$ & $35 \%$ & $50 \%$ \\
Storage reservation window & 24 & 12 & 8 & 4 & 1 \\
Maximum exchange & $10 \%$ & $20 \%$ & $30 \%$ & $40 \%$ & $50 \%$ \\
\hline
\end{tabular}

\section{Methodology}

\section{1 dynELMOD}

dynELMOD (dynamic Electricity Model) is a dynamic partial equilibrium model of the European electricity sector which determines cost-effective development pathways for the entire system. It endogenously decides upon investment in conventional and renewable generation, storage, DSM, and network capacities that influence the resulting dispatch. Electricity flows can be approximated using a flow-based market coupling approach, that accounts for loop-flows, or with a transport model. Due to computational complexity of balancing reservation, the transport model is used in this paper. The model dynamically optimizes the investments into generation and networks 
over the entire time horizon, but includes options to limit the planner's foresight to represent myopic investment behavior. A Carbon dioxide $\left(\mathrm{CO}_{2}\right)$ emission limit can be set for each year. The DIW Data Documentation by Gerbaulet and Lorenz (2017) provides a detailed description of the model.

The starting point for new investments is the currently available power plant portfolio, which decreases over time as the end of the lifetime of power plants are reached, and the existing electricity grid infrastructure. Further developments in the upcoming years are characterized by assumptions regarding the change of i) investment and operational cost, ii) fuel cost, iii) full load hours (FLH) of RES, iv) load and the $\mathrm{CO}_{2}$ emission limit. These developments form the boundary conditions, together with regional CCTS storage availability, overall and yearly investment limits and regional fuel availability.

In order to reduce complexity and proof generation adequacy the calculation is separated into two steps: in the first step, the investments are determined using a reduced time set for the dispatch calculations. To determine these hours, a time frame reduction technique that covers the characteristics of seasonal and time-of-day variations in the input parameters is included. In the second step, the investment decisions are fixed and evaluated based on a dispatch calculation with a full time set. This calculates the final generation and determines whether a reliable generation portfolio has been found that is adequate for the entire year.

\subsection{Extension of dynELMOD}

So far dynELMOD was focused on the electricity generation to cover the demand. This paper extends the model so that also the demand for reserves to balance short-term deviations will be included. The demand for balancing reserves is partly dependent on the installed capacities of fluctuating RES and hence endogenous within the model. The models does not only have to meet the electricity demand with the generation capacities but also the endogenous balancing reserve demand by partly withholding the same generation capacity.

The determination of the cost for balancing reserve provision will be done through a comparison of different calculation. The basis is always a calculation without balancing reserve provision, that is compared to calculations with balancing reserve provision within different technological and regulatory frameworks. The difference between the cost of the calculations thereby defines the cost for the provision of balancing reserves. Furthermore the cost increase due to balancing reserve provision can be differentiated into the different components like variable generation cost or investment cost.

Apart from the cost, a country specific reserve price can be determined. Still, power plant sharp prices can only be calculated ex-post. A further challenge in long-term investment models is a detailed approximation of flexibility constraints. Poncelet et al. (2014, 2016) analyze the problem of including short-term flexibility and balancing constraints into a long-term model. On the one hand, the reduced time-set, long-term investment models use, does often not represent the full variability of weather phenomena influencing the feed-in from RES. Increasing the time set would 
increase computation time intensively and is hence, only possible in simple models. Therefore large-scale models apply time reduction techniques (Green et al., 2014; Nahmmacher et al., 2016). On the other hand, some flexibility constraints like power plant status require binary variables. Introducing binary or integer variables in linear long-term investment models would significantly increase optimization time. A possible solution is to implement linear flexibility constraints (e.g. ramping restrictions) by linearization of the binary or integer constraints, which is also done in this approach.

In the following, the changes in the mathematical formulation to represent balancing provision are presented. Only the formulas that are new or changed in comparison to the basic dynELMOD will be shown here for simplicity. For the full mathematical formulation see Gerbaulet and Lorenz (2017).

Market clearing: I introduce two new market clearing conditions, one for positive reserves (1) and one for negative reserves (2). In every hour the necessary balancing reserves must be provided by generation capacities within the country or by reserve imports or exports to cover the surplus or deficits. The balancing reserve demand consists of an exogenous and an endogenous part: first, an exogenous part for load noise, schedule leaps and power plant failure that is based on historical reserve requirements. Second, an endogenous part, that depends on the scenario and is calculated based on either i) the installed capacity of non-dispatcheable RES (static sizing) or ii) the forecasted feed-in of non-dispatchable RES (dynamic sizing).

$$
\begin{aligned}
& \sum_{i} g_{c o, i, t, y}^{r e s v, p o s}=Q_{c o, t, y}^{r e s v, p o s}+\sum_{c c o} f l o w_{c c o, c o, t, y}^{r e s v, p o s} \\
& \left.+\sum_{y y \leq y, n d i s p} i n v_{c o, n d i s p, y y}^{c a p} \quad\right\} \text { Static Sizing } \quad \forall y, c o, t \\
& +\sum_{y y \leq y, n d i s p}{\operatorname{Res} A v a_{c o, t, n d i s p, y y}^{\text {newbilt }} * i n v_{c o, n d i s p, y y}^{c a p}}_{\}} \text {Dynamic Sizing } \\
& \sum_{i} g_{c o, i, t, y}^{r e s v, n e g}=Q_{c o, t, y}^{r e s v, n e g}+\sum_{c c o} f l o w_{c c o, c o, t, y}^{r e s v, n e g} \\
& \begin{array}{ll}
+\sum_{y y \leq y, n d i s p} i n v_{c o, n d i s p, y y}^{c a p} & \{\text { Static Sizing } \\
+\sum_{y y \leq y, n d i s p} \operatorname{ResAva} a_{c o, t, n d i s p, y y}^{\text {newbuilt }} * i n v_{c o, n d i s p, y y}^{c a p} & \} \text { Dynamic Sizing }
\end{array}
\end{aligned}
$$

Generation restrictions: Equations (3) and (4) define the reservation from dispatchable technologies. For these, the positive reservation is limited by the available generation capacity and current spot market production (Equations (5) and (6)). Furthermore dispatchable technologies (exept storage) must produce above minimum generation to provide positive reserves (7) and in addition at least the amount of negative reserves (8). 


$$
\begin{aligned}
& g_{\text {co }, \text { disp }, t, y}^{\text {resv }, \text { pos }}=\sum_{p} g_{p, \text { co,disp }, t, y}^{\text {resv }, \text { pos }, \text { xisting }}+\sum_{y y \leq y} g_{\text {cos,disp }, t, y, y y}^{\text {resv }, \text { pos }, \text { ewbuilt }} \quad \forall c o, \text { disp }, t, y
\end{aligned}
$$

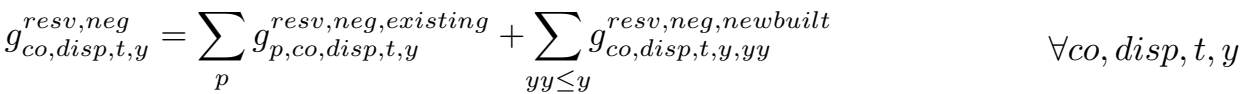

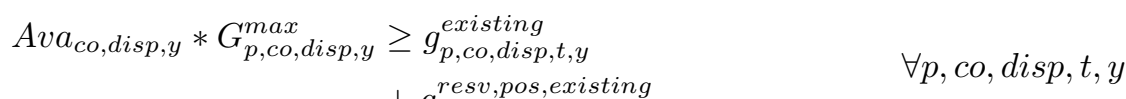

$$
\begin{aligned}
& +g_{p, c o, \text { disp }, t, y}^{r e s v} \text {, posing } \\
& A v a_{c o, d i s p, y} * i n v_{c o, d i s p, y y}^{c a p} \geq g_{c o, d i s p, t, y, y y}^{\text {newbuilt }} \\
& +g_{\text {co,disp, }, \text { res,yy }}^{\text {resv }, \text { pow }} \\
& \forall c o, d i s p, t, y, y y \\
& \begin{aligned}
g_{c o, i, t, y} * \frac{G_{p, c o, d i s p, y}^{\max }-G_{c, y}^{\min }}{G_{c, y}^{\min }} \geq g_{c o, d i s p, t, y}^{r e s v, p o s} & \forall c o, \text { disp } \notin s, t, y, y y \\
g_{c o, i, t, y}-G_{c, y}^{\text {min }} \geq g_{c o, d i s p, t, y}^{r e s v, n e g} & \forall c o, \text { disp } \notin s, t, y, y y
\end{aligned}
\end{aligned}
$$

The positive reserve provision by non-dispatchable RES is limited by their feed-in in equation (9). Furthermore the positive and negative reserve provision is limited to their firm capacity forecast of the feed-in (Equations (10) and (11)).

$$
\begin{aligned}
& g_{c o, n d i s p, t, y}+g_{\text {co }, n d i s p, t, y}^{\text {resvos }} \leq
\end{aligned}
$$

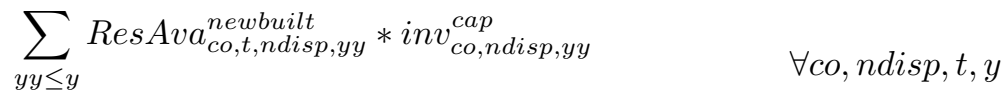

$$
\begin{aligned}
& +\sum_{p} \operatorname{Res} A v a_{c o, t, n d i s p}^{\text {existing }} * G_{p, c o, n d i s p, y}^{\max } \\
& g_{\text {co }, \text { ndisp }, t, y}^{\text {resv }, \text { os }} \leq g_{\text {co,ndisp }, t, y} * G_{\text {ndisp }, y}^{\text {safeshare }} \quad \forall c o, n d i s p, t, y, y y \\
& g_{\text {co,ndisp }, t, y}^{\text {resv }, n e g} \leq g_{\text {co,ndisp }, t, y} * G_{n d i s p, y}^{\text {safeshare }} \quad \forall c o, n d i s p, t, y, y y
\end{aligned}
$$

Ramping: Equations (12) and (13) define the maximum possible up and downward ramping taking into account the activation of reserves. Equation (14) and (15) enforce, that enough ramping capability is reserved so that reserves can be activated sufficiently fast.

$$
\begin{aligned}
& g_{\text {co }, i, t, y}^{\text {resv }, \text { up }}=g_{\text {co }, i, t, y}^{\text {resv }, \text { pos }}+g_{\text {co }, i, t-1, y}^{\text {resveg }} \quad \forall c o, i, t, y \\
& g_{\text {co }, i, t, y}^{\text {resv,down }}=g_{\text {co }, i, t, y}^{\text {reeveg }}+g_{\text {co }, i, t-1, y}^{\text {resv }, \text { pos }} \quad \forall c o, i, t, y \\
& g_{c o, c, t, y}^{u p}+g_{c o, i, t, y}^{r e s v, u p} \leq R_{i, y}^{u p} * \sum_{p} G_{p, c o, i, y}^{\max }+\sum_{y y \leq y} R_{i, y y}^{u p} * i n v_{c o, i, y y}^{c a p} \quad \forall c o, i, t, y \\
& g_{c o, i, t, y}^{\text {down }}+g_{c o, i, t, y}^{\text {resv,down }} \leq R_{i, y}^{\text {down }} * \sum_{p} G_{p, c o, i, y}^{\text {max }}+\sum_{y y \leq y} R_{i, y y}^{\text {down }} * i n v_{c o, i, y y}^{\text {cap }} \quad \forall c o, i, t, y
\end{aligned}
$$


Storage: The provision of positive and negative reserves by storages limit their maximum release and loading (Equations (16) and (17)). Still, their storage level does not change by balancing reservation, as the activation is still unknown (Equation (18)). However, it must be guaranteed, that the prevailing storage level is sufficiently high (low) to be able to provide positive (negative) reserves. These reserves must be provided for the consecutive hours comprised in the storage reservation window ( $T^{\text {window }}$ ) without violating maximum (19) or minimum (21) storage level constraints.

$$
\begin{aligned}
& \text { stor }{ }_{c o, s, t, y}^{\text {release }}+g_{c o, s, t, y}^{\text {resv, pos }} \leq A v a_{c o, s, y} * \text { Storage } \text { co }, s, y^{\text {maxrelease }} \\
& + \text { Ava }_{c o, s, y} * \text { Storage }_{c o, s, y}^{\text {maxrelease }} \quad \forall c o, s, t, y \\
& +A v a_{c o, s, y} * \sum_{y y \leq y} i n v_{c o, s, y y}^{c a p} \\
& \text { stor }_{c o, s, t, y}^{\text {loading }}+g_{c o, s, t, y}^{\text {resv,neg }} \leq \text { Ava }_{c o, s, y} * \text { Storage }_{c o, S, y}^{\text {maxloading }} \\
& + \text { Ava }_{c o, s, y} * \text { Storage }_{c o, S, y}^{\text {maxloading }} \quad \forall c o, s, t, y \\
& +A v a_{c o, s, y} * \sum_{y y \leq y} i n v_{c o, s, y y}^{c a p} \\
& \text { stor }_{c o, s, t, y}^{\text {level }}=\text { stor }_{c o, s, t-1, y}^{\text {level }}-\text { stor }_{c o, s, t, y}^{\text {Release }} \\
& +\eta_{c o, s, y}^{\text {storage }} * \text { stor }_{c o, s, t, y}^{\text {loading }} \quad \forall c o, s, t, y \\
& + \text { Inflow }_{c o, s, y, t} \\
& \text { stor }_{c o, s, t, y}^{\text {level }}+\sum_{t \geq t t \geq t-T^{\text {window }}} g_{c o s, t, y}^{\text {resveg }} \leq \text { Storage }_{c o, s, y}^{\text {maxlevel }}+\sum_{y y \leq y} \text { inv }_{c o, i, y y}^{\text {stor }} \quad \forall c o, s, t, y \\
& \text { stor }_{c o, s, t, y}^{\text {level }}-\sum_{t \geq t t \geq t-T^{\text {window }}} g_{c o s, s, p o s}^{\text {resv }} \geq \text { Storage }_{c o, s, y}^{\text {minlevel }} \quad \forall c o, s, t, y
\end{aligned}
$$

Network restrictions: The reservation of transmission capacity is always defined for both flow directions (Equation (22) and (23)). It should only lead to reductions of net transfer capacity (NTC) between countries, never to increased NTC for the spot market. This is realized by only taking the NTC-decreasing part of the reservation into account (Equation (24) and (25)). Therefore the model can not increase the NTC between countries by counter trading balancing reserves. Equations (26) to (29) therefore derive the positive and negative parts of the reserved capacities.

$$
f l o w_{c o, c c o, t, y}^{\text {resv }, \text { os }}=-f l o w_{c c o, c o, t, y}^{\text {resv }, \text { os }} \quad \forall c o, c c o, t, y
$$




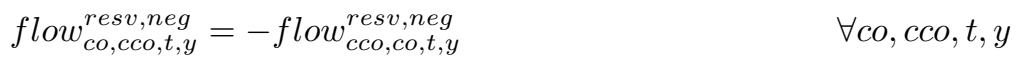

$$
\begin{aligned}
& \begin{aligned}
N T C_{c o, c c o}+i n v_{y, c o, c c o}^{l i n e} & \geq \text { flow }_{c o, c c o, t, y}+\text { flow }_{c o, c c o, t, y}^{\text {resv }, \text { os }, g e 0} \\
& -f_{\text {low }}^{\text {resv }, \text { neg }, l e 0}
\end{aligned} \quad \forall c o, c c o, t, y \\
& -N T C_{c o, c c o}-i n v_{y, c o, c c o}^{\text {line }} \leq \text { flow }_{c o, c c o, t, y}+\text { flow }_{c o, c c o, t, y}^{\text {resv }, \text { pos }} \\
& \text { - flow } \text { cos }, \text { cco, }, \text {, }, y^{\text {rege }} \\
& \forall c o, c c o, t, y \\
& f_{l o w}^{\text {resv,pos,ge0 }} \geq \text { flow }_{\text {co,cco }, t, y}^{\text {resv }, \text { pos }} \quad \forall c o, c c o, t, y \\
& \text { flow }_{\text {co }, \text { cco }, t, y}^{\text {resv }, \text { ge0 }} \geq \text { flow }_{\text {co,cco,t,y }}^{\text {resv }, \text { eg }} \quad \forall c o, c c o, t, y \\
& \text { flow }_{c o, c c o, t, y}^{\text {resv }, \text { pos }, l e 0} \leq \text { flow }_{\text {co,cco }, t, y}^{\text {resv }, \text { pos }} \quad \forall c o, c c o, t, y
\end{aligned}
$$

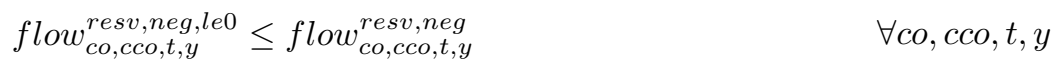

Model Limitations: When interpreting the results one has to bear in mind the model structure. On the one hand, not the all flexibility constraints can be included in a linear model with a country-sharp resolution. On the other hand, no strategic behavior can be included, which can be an important price driver in the market setting. Therefore, the costs of balancing provision may be underestimated. However relative cost changes between different scenarios remain valid.

This model abstracts from different types of balancing reserves. It does not differentiate between FCR, aFRR and mFRR nor between spinning and non-spinning reserves. On the one hand, this would significantly increase computational time. On the other hand it is not clear, how the additional balancing reserve demand from fluctuating RES demand will be allocated to the different types of balancing reserves. Therefore, using different reserve types could distort results and pertinence a false precision. Furthermore the influence of different reserve types is reduced, as two main sources for future balancing reserve provision are anyhow either spinning (fluctuating RES) or very flexible and able to provide FCR (storages).

The amount of balancing reserves that will be activated is not known beforehand. Hence, this model only includes the cost for the reservation and neglects the cost for the activation of reserves. Still the model formulation assures, that for all hours, sufficient capacity is available to allow for positive or negative reservation. Dependent on the volumes of positive and negative activation, the TSC could be increased or lowered.

\section{Data and application}

I apply the extended version of dynELMOD to an European data set described in Gerbaulet and Lorenz (2017). As long as not stated otherwise all data used for this application based on 
this dataset, is published under open-source license together with the model. ${ }^{1}$ Therefore, in the following, only a short summary of the data will be given.

The data-set is defined for the periode from 2015 to 2050 in five-year steps. It includes 33 different countries in five synchronous areas, each country represented by one node. It represents 31 different generation technologies: ten conventional, nine renewable, five CCTS and seven storage (including four DSM) technologies as well as their future development regarding cost and efficiencies. For existing capacities, a decommissioning path is calculated based on assumptions for lifetimes and each power plant block's commissioning date. Potentials for CCTS are included on a country resolution. The data set includes demand and renewable feed-in time series spanning 8,760 hours from the year 2013 for each country. These are scaled individually to meet the different FLH for each country of the upcoming years.

The $\mathrm{CO}_{2}$ emission pathway is based on based on the scenario "Diversified supply technologies" from the European Commission's Energy Roadmap 2050 - Impact Assessment and scenario analysis (EC, 2011). As dynELMOD only covers the electricity sector, the $\mathrm{CO}_{2}$ pathway that sets a limit on yearly $\mathrm{CO}_{2}$ emissions allocated to the electricity sector is used. The usage of such a strict $\mathrm{CO}_{2}$ emission pathway is a main driver of the resulting transformation of the generation portfolio. Furthermore no banking of $\mathrm{CO}_{2}$ emissions is allowed between the periods.

Prices for coal, gas and oil and their development until 2050 are based on the "EU Reference Scenario 2016" by EC (2016).

\section{Results}

The transformation pathway for the electricity sector, provided by the model results of dynELMOD, will be looked at first, as it sets the stage for the balancing reserve provision. I analyze the installed capacities and resulting electricity generation before taking a closer look at the cost and technology structure of the balancing reserve provision.

Figure 2 shows the development of the installed capacities from 2020 to 2050 in Europe. The total installed capacity increases from 1,100 GW in 2020 to 2,900 GW in 2050. This steep increase can be explained by the, on average, lower FLH of RES compared to fossil fired power plants. In 2050, $870 \mathrm{GW}$ of solar PV, $740 \mathrm{GW}$ wind onshore and $270 \mathrm{GW}$ of wind offshore make up for the major share of the generation portfolio. No new nuclear, lignite, or hard coal fired capacities are constructed, which results in a nearly complete phase-out for those technologies until 2050. The fluctuating generation from RES is evened out with $465 \mathrm{GW}$ of storage capacity which includes batteries, power to gas and DSM. During extreme hours, natural gas fired power plant capacities, with $215 \mathrm{GW}$, serve as backup capacities.

Resulting from the developments of the generation portfolio, the electricity mix changes from 2020 to 2050 as shown in Figure 3. In 2050 more than $95 \%$ of the electricity generation is renewable. Onshore wind is the biggest producer with a share of more than one third while the

\footnotetext{
${ }^{1}$ http://diw.de/elmod\#dynELMOD
} 


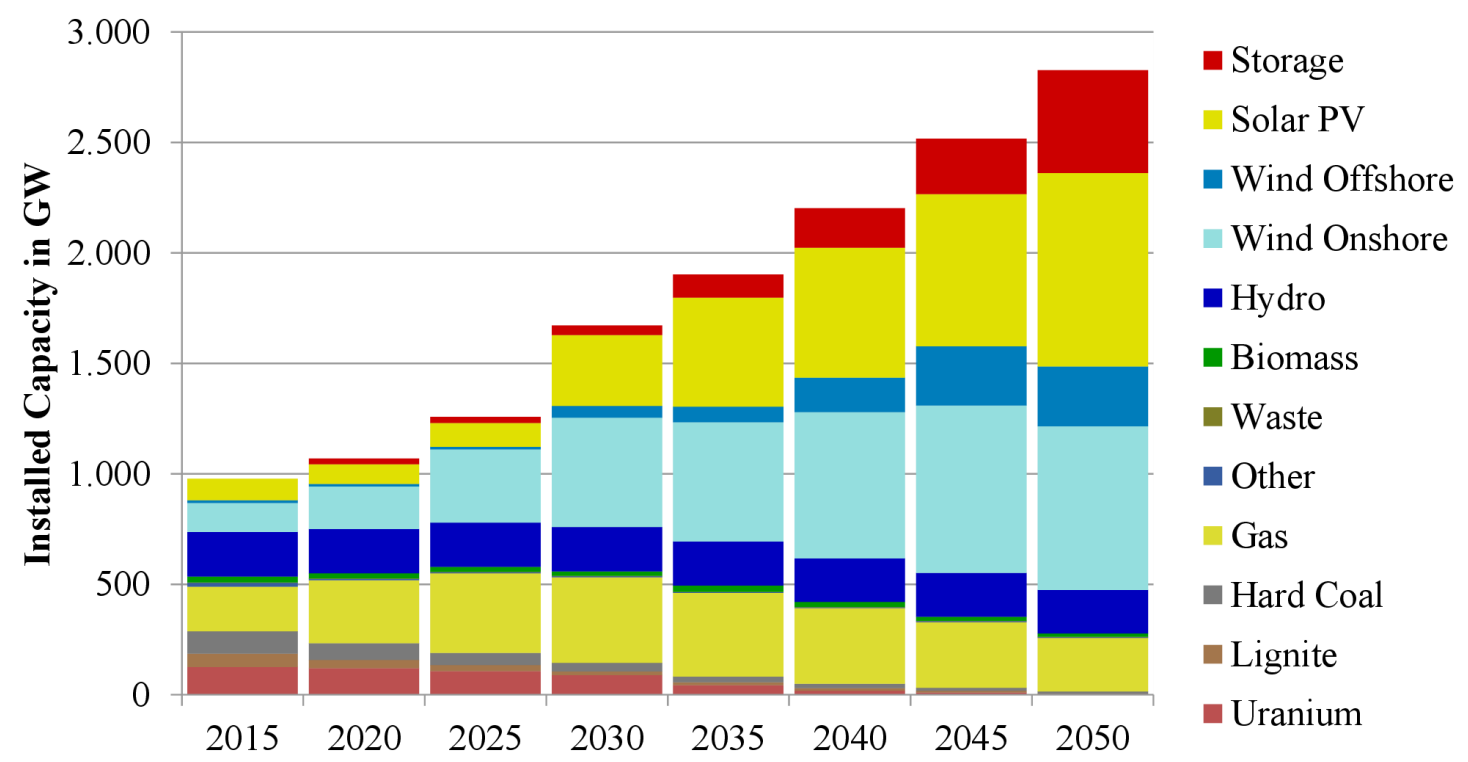

Figure 2: Installed electricity generation and storage capacities in Europe until 2050

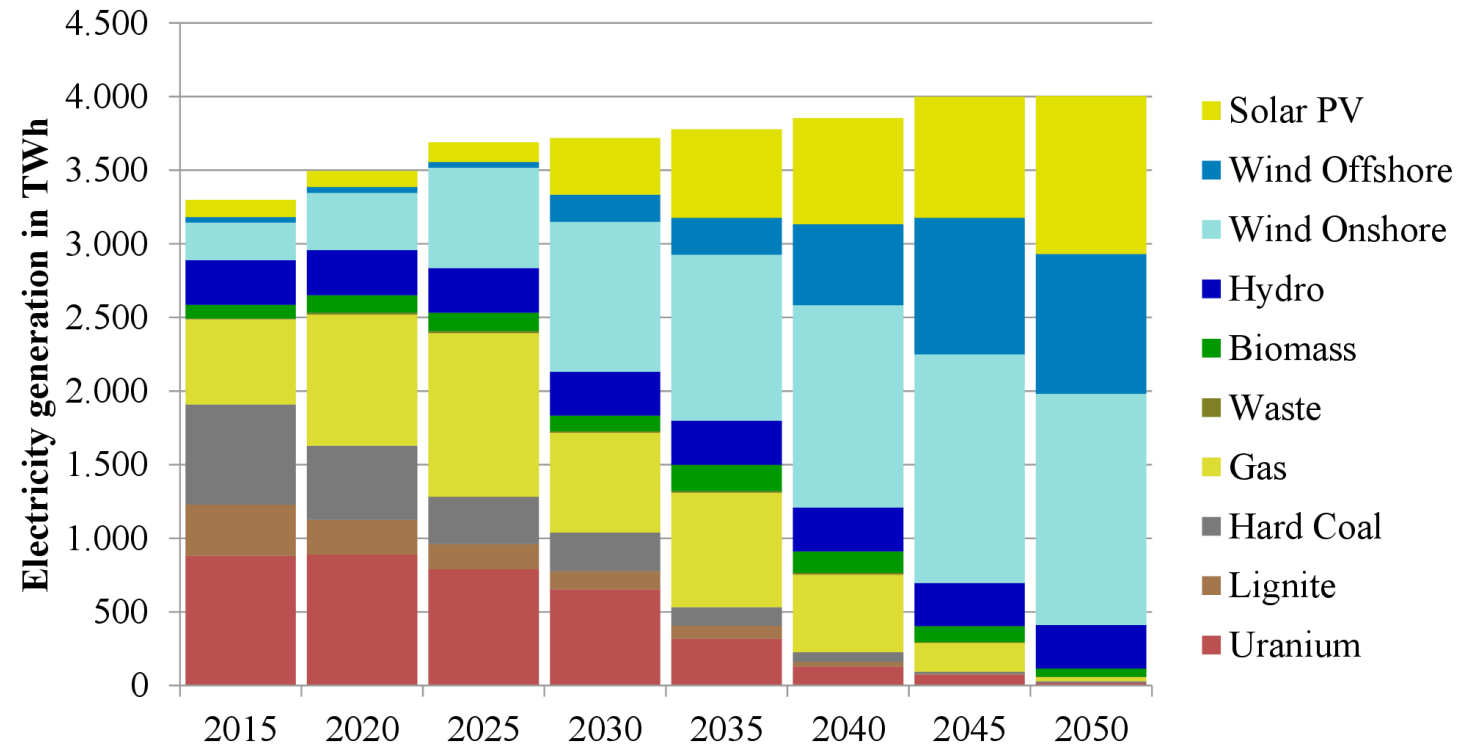

Figure 3: Electricity generation in Europe until 2050 
share of offshore wind and solar PV reach one quarter. An additional source of flexibility is transmission capacity that allows to use the spatial variability of demand and RES supply. As this is not the focus of this paper, the resulting transmission expansion will not by analyzed. A detailed analysis can be found in Gerbaulet and Lorenz (2017).

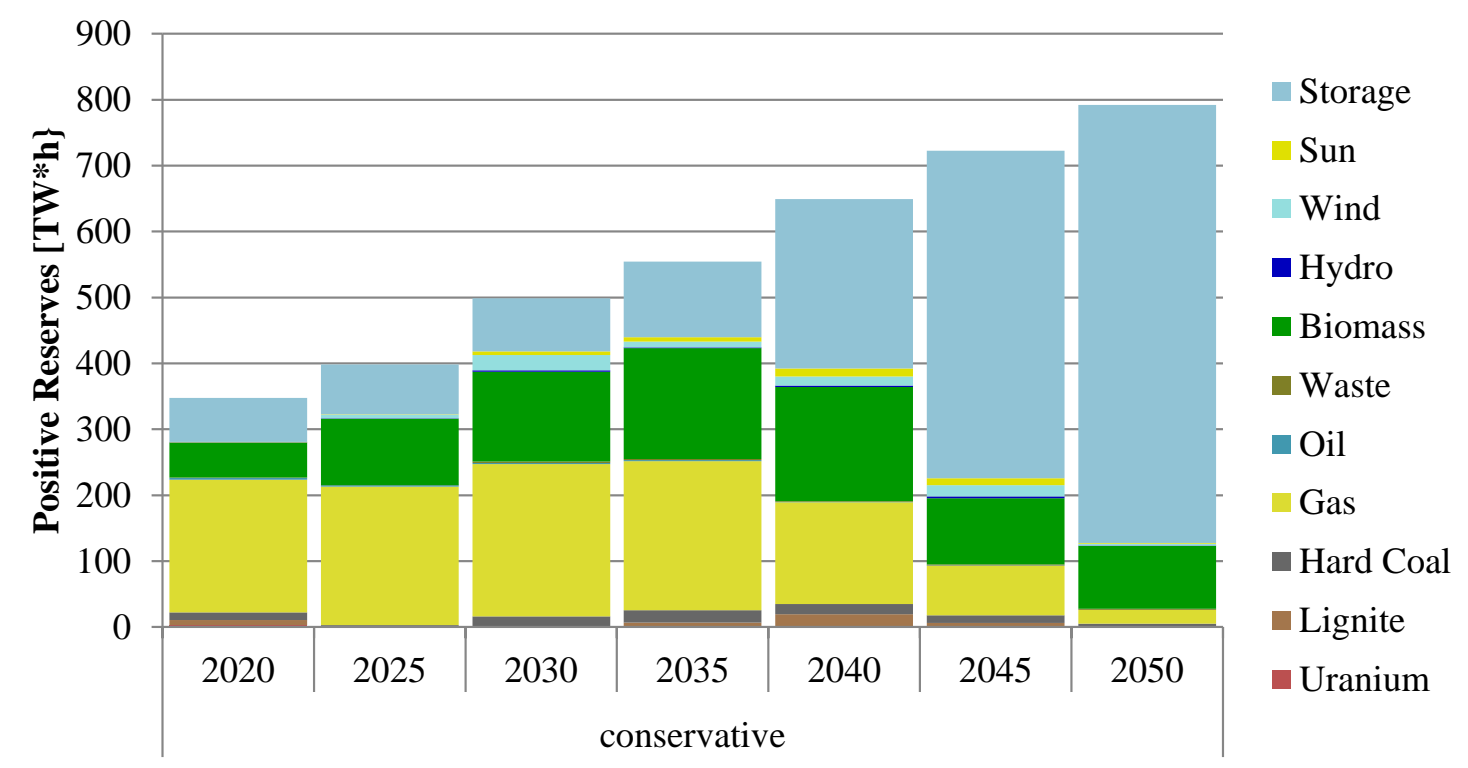

Figure 4: Positive balancing provision in Europe from 2020 to 2050

Figure 4 shows the provision of positive reserves by different technologies in the different years. Despite a dynamic sizing horizon, the total volume of positive balancing reserves more than doubles until 2050, still the electricity demand increases by less then $20 \%$. This can be traced back to the balancing reserve demand caused by increased generation capacities from fluctuating RES. The provision by storages is increases rapidly from 2035 onwards and accounts for the largest share in 2040. In contrast, the provision by fluctuating RES is very low. It is most of the time not beneficial to curtail fluctuating RES just to provide positive reserves as there is sufficient storage and demand flexibility in the fully interconnected European electricity system to store or use it. The provision by biomass peaks in 2035, when the provision by gas fired capacities starts to decrease rapidly. Biomass retains a much higher share than gas in 2050, as the minimum generation restrictions during balancing provision reduces the possibility for gas largely due to the $\mathrm{CO}_{2}$ constraint.

The total volume of negative balancing reserves more than doubles until 2050, due to the same reasons as the positive balancing reserves. However, in contrast to positive balancing reserves, the negative balancing reserves are mainly provided by fluctuating RES from 2040 onwards (Figure 5). From 2035 on, wind (on- and offshore) has the largest share, while PV also participates but to a lesser extent. The dominance of fluctuating RES can be explained by their very low opportunity cost to provide negative reserves, as they have no marginal generation cost and are therefore 


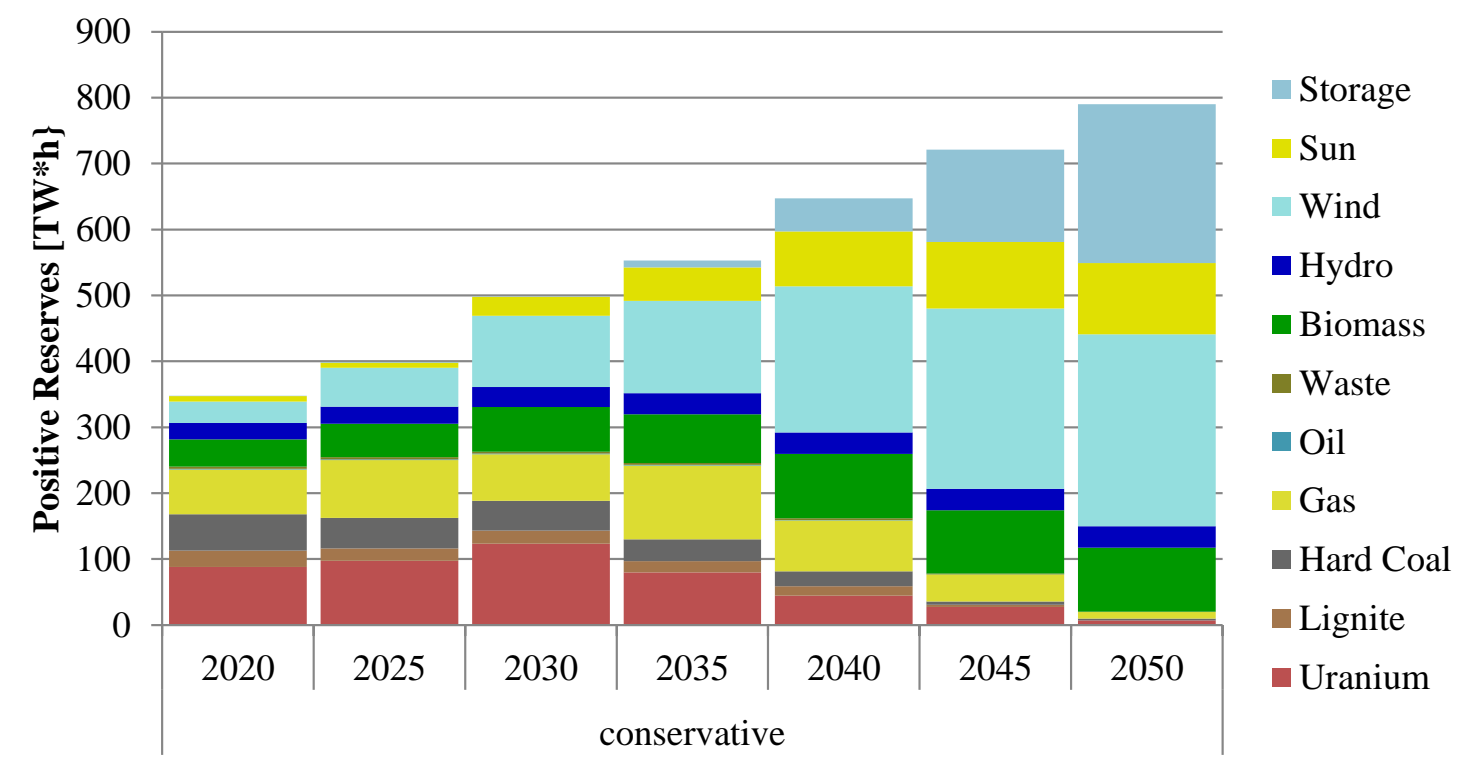

Figure 5: Negative balancing provision in Europe from 2020 to 2050

dispatched first. Also storages, which increase their share from 2040 on, have very low opportunity cost as they can use their recharge capability to provide negative reserves. The provision by nuclear, coal and gas is gradually reduced, in line with their diminishing share in the spot market (compare Figure 3).

The results show that balancing reserve cost (shown in figure 6) does not have to increase due to a fully renewable electricity system. When comparing the calculated balancing cost to the observed balancing cost range in Europe in 2015 (ACER and CEER, 2016), no increase can be identified. As most important factor, the choice between a static or a dynamic sizing horizon determines the cost. With a static horizon, cost are up to five times higher than for a dynamic sizing horizon. Even within an optimistic technical and regulatory framework the statical sizing horizon would result in $70 \%$ higher cost compared to the dynamic sizing horizon within a pessimistic framework. Both, additional generation and investment cost would be much lower in the dynamic sizing horizon. This is due to the very high share of RES in 2050, for which in the static case also during hours with low RES feed-in, reserves for the entire installed capacity must be reserved. During these times of low RES feed-in, reserve provision is costly, as dispatchable generation capacities are necessary for electricity production and hence have high opportunity cost when providing balancing reserves. Therefore a static balancing reserve demand would cause additional investments and higher generation capacity in the static sizing horizon. With a dynamic sizing horizon balancing reserve provision cost are ranging from $0.7 \%$ and $2 \%$ of the TSC $(0.5 € / \mathrm{MWh}$ to $1.5 € / \mathrm{MWh}$ of electricity generation) depending on the assumptions for the technical and regulatory framework. Despite the large importance of the sizing horizon on the cost, the remaining technical and regulatory developments are crucial to keep cost down. 


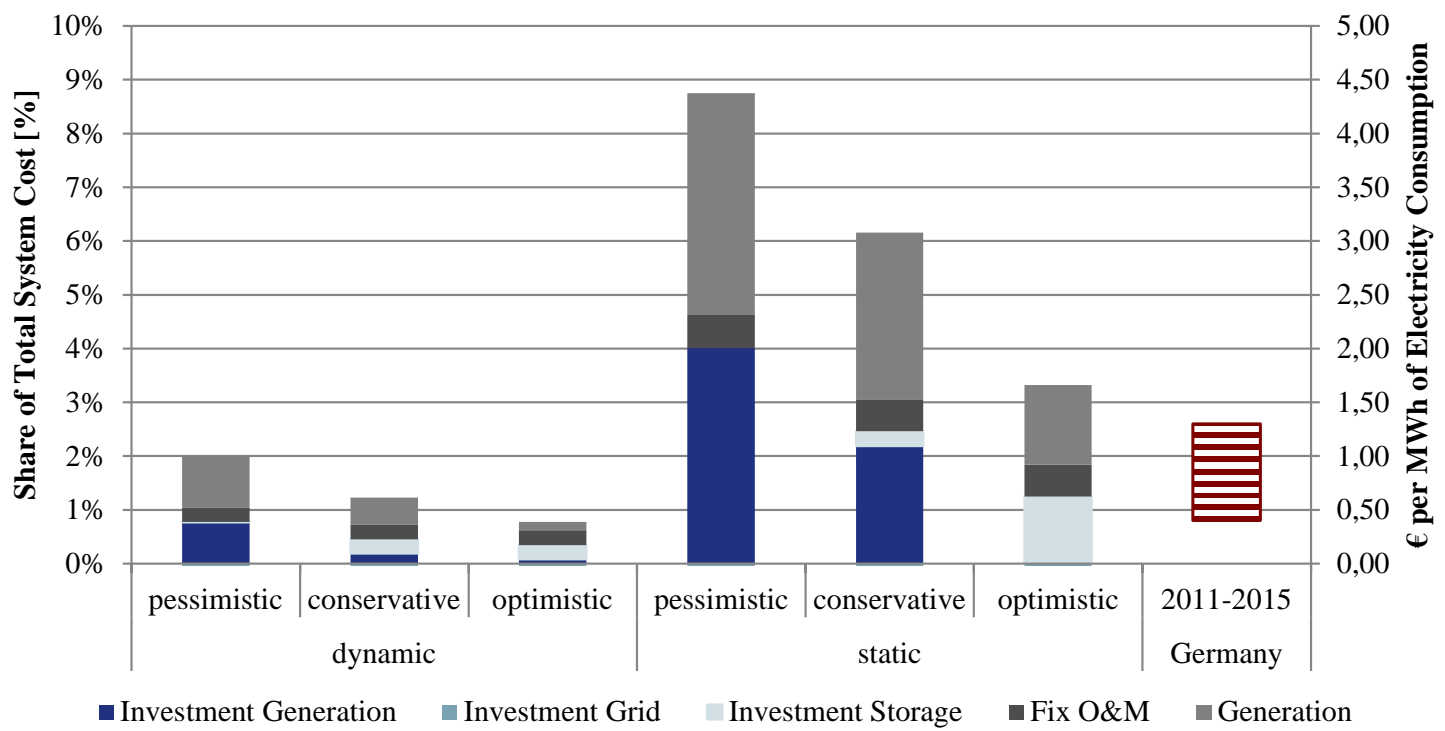

Figure 6: Electricity balancing cost in Europe until 2050

With ambitious technical and regulatory developments in the optimistic scenario cost savings of up to $60 \%$ compared to the pessimistic scenario can be realized. However, even with pessimistic assumptions regarding the framework development, the cost for balancing reserve provision does not rise above the cost observed between 2011 and 2015 in Germany. ${ }^{2}$ When comparing the cost components of the balancing reserve provision cost, variable generation cost are the biggest component for all scenario combinations. Furthermore the relative shares of the components are similar between the static and dynamic sizing horizon.

When comparing the large share of positive balancing reserves that are provided by storages, to the low additional investments into storages caused by balancing reserve provision, it becomes clear, that there are large flexible capacities left in the system. These capacities are mainly storages, required to even out daily and seasonal variations of RES availability. As these storage capacities are not fully used during most of the time, they can provide balancing reserves at very low opportunity cost. Hence, only for very few occasions additional storage or other dispatchable capacities are necessary for balancing reserve provision.

The costs for balancing reserve provision show different sensitivities with respect to the developments of the technical and regulatory framework. All sensitivities shown in Figure 7 are assessed against the development that is assumed in the conservative scenario. The assumptions regarding the length of the storage reservation window have the biggest influence on balancing cost. With long durations, less reserves can be provided by storages and hence additional generation capacity becomes necessary. When the additional generation capacity is used to provide reserves their minimum run constraints cause additional variable generations. When looking at the cost components it becomes clear, that below a storage reservation window of eight hours no additional

\footnotetext{
${ }^{2}$ The model abstracts from strategic behavior and therefore the cost are likely to be a lower bound.
} 


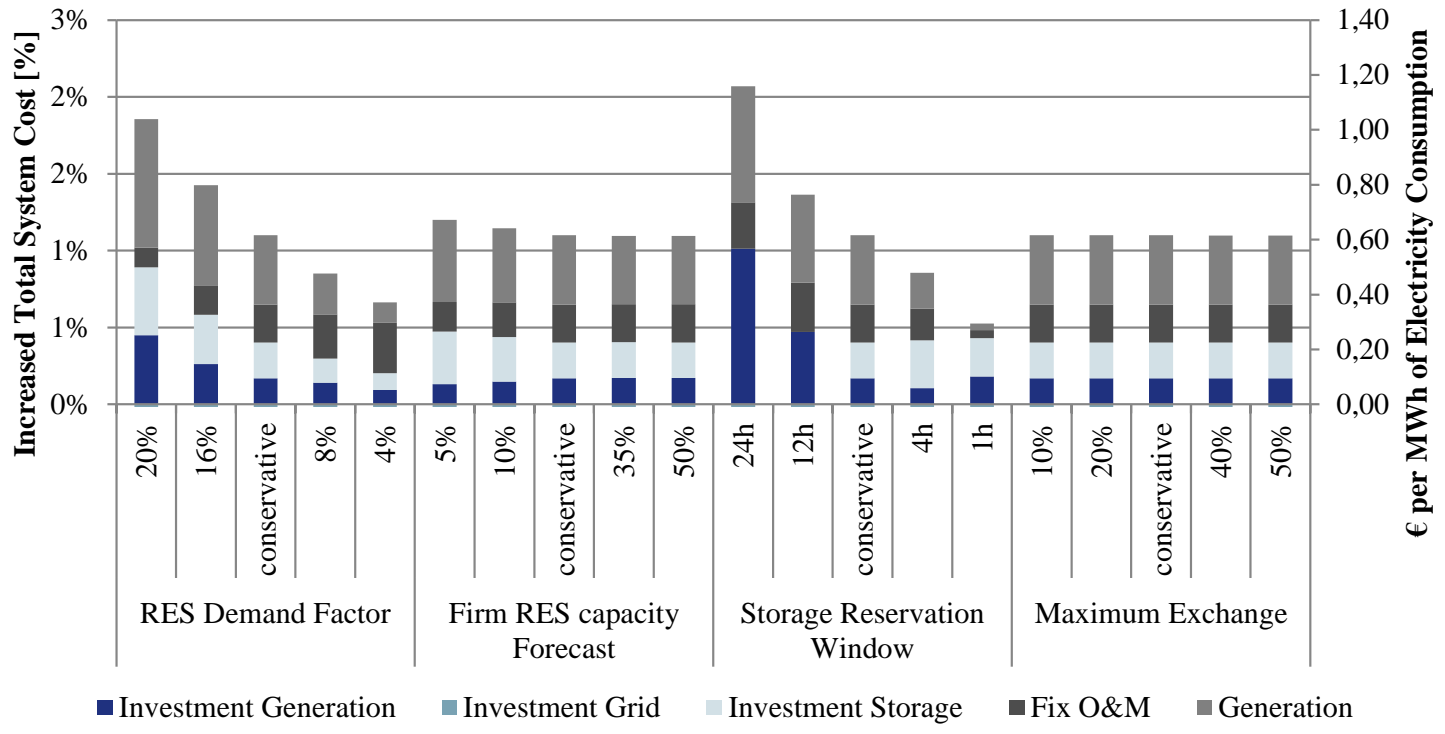

Figure 7: Sensitivities of electricity balancing cost in Europe until 2050

storage capacity will be built for balancing reserve provision in comparison to a neglection of those reserves. In sum, a very long storage reservation window can nearly double the cost for balancing reserve provision.

When the RES demand factor is increased up to $20 \%$, the balancing reserve demand increases in comparison to the conservative scenario. A higher balancing reserve demand in turn leads to higher overall cost. In total, cost can increase by nearly $60 \%$, while the shares of the cost components remain constant.

In comparison to the RES demand factor, the influence of the firm RES capacity forecast is much lower. A firm capacity of only five percent, in comparison to the conservative scenario with $20 \%$ firm capacity, causes only minor balancing reserve cost increase of less then $10 \%$. A firm forecast of only $10 \%$ of the RES capacity is already sufficient for balancing reserve provision. This can be explained by the high share of storage used for positive reserves provision and RES providing mainly negative reserves.

A limitation on the exchange of balancing reserves (the share of the balancing demand that is covered by imports) has the lowest impact on the balancing reserve provision cost. This unintuitive result can be explained by a rather even distribution of storage capacities over Europe until 2050. These storage capacities allow for positive balancing reserve provision independent from the generation portfolio of the country. Nevertheless before a large deployment of storages the exchange of balancing reserves can lead to large efficiency gains. 


\section{Conclusion}

The decarbonization of the electricity sector also influences the future of balancing reserve provision. Therefore, the balancing provision is analyzed in a long-term perspective of a fully renewable electricity system. The developments of the technical and regulatory framework of future balancing reserve provision are subject to large uncertainties. This paper applies a dynamic investment model of the European electricity sector to analyze the cost and effects of the future balancing reserve provision.

The results show that balancing reserve cost can be kept at current levels for a renewable electricity system until 2050. This requires no optimistic developments of the technical and regulatory framework, however a dynamic reserve sizing horizon is of importance to keep costs down. Apart from the sizing horizon, storage capacity withholding duration, and additional balancing demand from RES are the main drivers of balancing costs. RES participation in balancing provision is mainly important for negative reserves, while storages play an important role for the provision of positive reserves. However, only for very few occasions, additional storage investments are required for balancing reserve provision, as most of the time sufficient storage capacities are available in the electricity system.

\section{Acknowledgment}

The author would like to thank Clemens Gerbaulet and Alexander Zerrahn for valuable comments and support. The author gratefully thanks the Reiner Lemoine-Stiftung for financing his research work.

\section{References}

50Hertz, APG, Amprion, Elia, TenneT, and TransnetBW (2016). EXPLORE - Target model for exchange of frequency restoration reserves. URL: https://www. entsoe. eu/Documents/Ne twork\%20codes\%20documents/Implementation/EXPLORE/20161021_EXPLORE_FRR_TARGET_ MODEL.PDF?Web=1 (visited on February 3, 2017).

50Hertz (2016). Wind farms can participate in balancing market. Press Release. Berlin. URL: http : / / www . 50hertz . com / Portals / 3 / Content / NewsXSP / 50hertz_flux / Dokumente / 20160217_PM_50Hertz_Praequalifizierung_Windkraft_EN.pdf.

ACER and CEER (2016). Annual Report on the Results of Monitoring the Internal Electricity Markets in 2015. Luxembourg. URL: http://www. acer.europa.eu/official_documents/ acts_of_the_agency/publication/acer $\% 20$ market $\% 20$ monitoring $\% 20$ report $\% 202015 \% 20$ $\% 20$ lectricity.pdf.

Belderbos, A. and E. Delarue (2015). Accounting for flexibility in power system planning with renewables. International Journal of Electrical Power $\& 3$ Energy Systems 71, 33-41. 
Brijs, T., A. v. Stiphout, S. Siddiqui, and R. Belmans (2016). Evaluating the role of electricity storage by considering short-term operation in long-term planning. DIW Discussion Paper 1624. Berlin. URL: https://www.diw.de/documents/publikationen/73/diw_01.c.548146.de/ dp1624.pdf.

Brouwer, A. S., M. van den Broek, A. Seebregts, and A. Faaij (2014). Impacts of large-scale Intermittent Renewable Energy Sources on electricity systems, and how these can be modeled. Renewable and Sustainable Energy Reviews 33, 443-466.

Bucksteeg, M., L. Niesen, and C. Weber (2016). Impacts of Dynamic Probabilistic Reserve Sizing Techniques on Reserve Requirements and System Costs. IEEE Transactions on Sustainable Energy 7(4), 1408-1420.

dena (2010). dena-Netzstudie II - Integration erneuerbarer Energien in die deutsche Stromversorgung im Zeitraum 2015-2020 mit Ausblick auf 2025. Endbericht. Berlin, Germany. URL: http://www.dena.de/fileadmin/user_upload/Publikationen/Erneuerbare/Dokumente/ Endbericht_dena-Netzstudie_II.PDF (visited on September 14, 2016).

DLR (2012). Langfristszenarien und Strategien für den Ausbau der erneuerbaren Energien in Deutschland bei Berücksichtigung der Entwicklung in Europa und global. Schlussbericht BMU FKZ 03MAP146. 345 pp. URL: http://www.dlr.de/dlr/Portaldata/1/Resources/bilder/ portal/portal_2012_1/leitstudie2011_bf.pdf (visited on October 24, 2016).

EC (2011). Energy Roadmap 2050 - Impact Assessment and scenario analysis. SEC(2011) 1565 final. Brussels, Belgium. URL: https : / / ec . europa . eu / energy / sites / ener / files / documents/roadmap2050_ia_20120430_en_0.pdf (visited on October 24, 2016).

EC (2016). EU Reference Scenario 2016: Energy, transport and GHG emissions - Trends to 2050. Brussels, Belgium. URL: https://ec. europa.eu/energy/sites/ener/files/documents/ REF2016_report_FINAL-web.pdf (visited on September 16, 2016).

EC (2017). Commission regulation (EU) establishing a guideline on electricity balancing. Final Draft. Brussels, Belgium. URL: https : / / ec . europa . eu / energy / sites / ener / files / documents/informal_service_level_ebgl_24-01-2017.pdf (visited on January 30, 2017).

ENTSO-E (2012). Survey on Ancillary Services Procurement $\mathscr{B}$ Balancing market design. Brussels, Belgium. URL: https://www. entsoe.eu/fileadmin/user_upload/_library/resources/ BAL/121022_Survey_on_AS_Procurement_and_EBM_design.pdf (visited on December 9, 2013).

ENTSO-E (2014). Balancing Pilot Projects. Third Cross Border Balancing Pilot Projects Stakeholder Meetings. Brussels, Belgium. URL: https://www.entsoe.eu/Documents/Network\% 20codes\%20documents/Implementation/Pilot_Projects/141217_CBB_pilot_projects_ overview.pdf (visited on September 15, 2016). 
ENTSO-E (2015). Cross Border Electricity Balancing Pilot Project 4. 2 Month Report. Brussels, Belgium. URL: https : / / www . entsoe . eu / Documents / Network\%20codes \%20documents / Implementation/Pilot_Projects/151130_Report_P4.pdf.

EWEA (2014). Economic grid support services by wind and solar PV - a review of system needs, technology options, economic benefits and suitable market mechanisms. Brussels. URL: https: //windeurope.org/fileadmin/files/library/publications/reports/REserviceS.pdf.

Farahmand, H. and G. Doorman (2012). Balancing market integration in the Northern European continent. Applied Energy 96. Special Issue "Smart Grids", 316-326.

Fleer, J., S. Zurmühlen, J. Badeda, P. Stenzel, J.-F. Hake, and D. U. Sauer (2016). Model-based Economic Assessment of Stationary Battery Systems Providing Primary Control Reserve. Energy Procedia 99, 11-24.

Fraunhofer IWES (2014). Regelenergie durch Windkraftanlagen. Projekt im Auftrag des Bundesministeriums für Umwelt, Naturschutz, Bau und Reaktorsicherheit. Kassel. URL: http: //www . energiesystemtechnik. iwes.fraunhofer.de/content/dam/iwes-neu/energies ystemtechnik/de/Dokumente/Studien-Reports/20140822_Abschlussbericht_rev1.pdf (visited on October 17, 2016).

Gebrekiros, Y., G. Doorman, S. Jaehnert, and H. Farahmand (2015). Reserve procurement and transmission capacity reservation in the Northern European power market. International Journal of Electrical Power 8 Energy Systems 67, 546-559.

Gerbaulet, C. and C. Lorenz (2017). dynELMOD: A Dynamic Investment and Dispatch Model for the Future European Electricity Market. DIW Berlin, Data Documentation 88. Berlin, Germany.

Gesino, A. J. (2011). Power reserve provision with wind farms: Grid integrations of wind power. OCLC: 846227619. Kassel: Kassel Univ. Press. 162 pp.

Götz, A. and B. Baumgart (2014). Windenergie am Regelleistungsmarkt. Energiewirtschaftliche Tagesfragen 64(4), 13-17.

Green, R., I. Staffell, and N. Vasilakos (2014). Divide and Conquer? k-Means Clustering of Demand Data Allows Rapid and Accurate Simulations of the British Electricity System. IEEE Transactions on Engineering Management 61(2), 251-260.

Hagspiel, S., C. Jägemann, D. Lindenberger, T. Brown, S. Cherevatskiy, and E. Tröster (2014). Cost-optimal power system extension under flow-based market coupling. Energy 66, 654-666.

Hirth, L. and I. Ziegenhagen (2015). Balancing power and variable renewables: Three links. Renewable and Sustainable Energy Reviews 50, 1035-1051.

Holttinen, H., P. Meibom, A. Orths, B. Lange, M. O’Malley, J. O. Tande, A. Estanqueiro, E. Gomez, L. Söder, G. Strbac, J. C. Smith, and F. van Hulle (2011). Impacts of large amounts of wind power on design and operation of power systems, results of IEA collaboration. Wind Energy 14(2), 179-192. 
Holttinen, H., M. Milligan, E. Ela, N. Menemenlis, J. Dobschinski, B. Rawn, R. J. Bessa, D. Flynn, E. Gomez-Lazaro, and N. K. Detlefsen (2012). Methodologies to Determine Operating Reserves Due to Increased Wind Power. IEEE Transactions on Sustainable Energy 3(4), 713-723.

Jansen, M. and M. Speckmann (2013). Participation of photovoltaic systems in control reserve markets. Institution of Engineering and Technology, 0245-0245.

Kays, J., J. Schwippe, D. Waniek, and C. Rehtanz (2010). Multidimensionales Verfahren zur Bestimmung des Regelleistungsbedarfes unter Berücksichtigung von Unsicherheiten. Zeitschrift für Energiewirtschaft 34(4), 267-278.

Lew, D., G. Brinkman, E. Ibanez, B. M. Hodge, and J. King (2013). The western wind and solar integration study phase 2. Technical Report NREL/TP-5500-55588. Golden, CO, USA. URL: http://www.nrel.gov/docs/fy13osti/55588.pdf (visited on October 24, 2016).

Lorenz, C. and C. Gerbaulet (2017). Options for Cross-border balancing reserve provision. DIW Berlin, Discussion Paper forthcoming. Berlin, Germany. (Visited on ).

Ludig, S., M. Haller, E. Schmid, and N. Bauer (2011). Fluctuating renewables in a long-term climate change mitigation strategy. Energy 36(11), 6674-6685.

Mantzos, L. and T. Wiesenthal (2016). POTEnCIA model description: version 0.9. Luxembourg: EC Publications Office.

Morbee, J., J. Driesen, K. De Vos, and R. Belmans (2013). Impact of wind power on sizing and allocation of reserve requirements. IET Renewable Power Generation 7(1), 1-9.

Nahmmacher, P., E. Schmid, L. Hirth, and B. Knopf (2016). Carpe diem: A novel approach to select representative days for long-term power system modeling. Energy 112, 430-442.

Nykvist, B. and M. Nilsson (2015). Rapidly falling costs of battery packs for electric vehicles. Nature Climate Change 5(4), 329-332.

Ortega-Vazquez, M. A. and D. S. Kirschen (2009). Estimating the spinning reserve requirements in systems with significant wind power generation penetration. IEEE.

Papavasiliou, A., S. S. Oren, and R. P. O'Neill (2011). Reserve Requirements for Wind Power Integration: A Scenario-Based Stochastic Programming Framework. IEEE Transactions on Power Systems 26(4), 2197-2206.

Poncelet, K., E. Delarue, J. Duerinck, D. Six, and W. D'haeseleer (2014). The importance of integrating the variability of renewables in long-term energy planning models. TME Working Paper - Energy and Environment EN2014-20. Leuven, Belgium. URL: https://www . mech . kuleuven.be/en/tme/research/energy_environment/Pdf/wp-importance.pdf (visited on April 18, 2016).

Poncelet, K., E. Delarue, D. Six, J. Duerinck, and W. D'haeseleer (2016). Impact of the level of temporal and operational detail in energy-system planning models. Applied Energy 162, 631-643. 
Sorknæs, P., A. N. Andersen, J. Tang, and S. Strøm (2013). Market integration of wind power in electricity system balancing. Energy Strategy Reviews 1(3), 174-180.

Spieker, S., J. Kopiske, and G. Tsatsaronis (2016). Flexibilität aus Wind-und Photovoltaikanlagen im Regelenergiemarkt 2035. 14. Symposium Energieinnovation. Graz, Austria.

van Stiphout, A., K. De Vos, and G. Deconinck (2017). The Impact of Operating Reserves on Investment Planning of Renewable Power Systems. IEEE Transactions on Power Systems 32(1), 378-388.

UNFCCC (2015). Paris Agreement. UR L: http://unfccc.int/files/meetings/paris_nov_ 2015/application/pdf/paris_agreement_english_.pdf (visited on September 21, 2016).

van der Veen, R. A. C., A. Abbasy, and R. A. Hakvoort (2010). A qualitative analysis of main cross-border balancing arrangements. 7th International Conference on the European Energy Market, 1-6.

Zerrahn, A. and W.-P. Schill (2015). A Greenfield model to evaluate long-run power storage requirements for high shares of renewables. DIW Berlin, Discussion Paper 1457. Berlin, Germany. URL: https://www.diw.de/documents/publikationen/73/diw_01.c.498475 .de/dp1457 . pdf (visited on April 19, 2016).

Ziegenhagen, I. (2013). Impact of Increasing Wind and PV Penetration Rates on Control Power Capacity Requirements in Germany. MA thesis. Institut für Infrastruktur und Ressourcenmanagement, Universität Leipzig. 